\title{
Bite Force Comparison of Implant-retained Mandibular Overdentures with Conventional Complete Dentures: An in vivo Study
}

\author{
${ }^{1}$ AS Kaul, ${ }^{2}$ Deepak Goyal \\ ${ }^{1}$ Professor and Head, Department of Prosthodontics, KD Dental College, Mathura, Uttar Pradesh, India \\ ${ }^{2}$ Postgraduate Student, Department of Prosthodontics, KD Dental College, Mathura, Uttar Pradesh, India
}

Correspondence: Deepak Goyal, Postgraduate Student, Department of Prosthodontics, KD Dental College, Mathura, Uttar Pradesh, India, e-mail: goyal.drdeepak@gmail.com

\begin{abstract}
Patients wearing conventional dentures often complain about the instability of the prosthesis, particularly the mandibular denture. Denture instability leads to feeling of insecurity, inefficient mastication, and overall dissatisfaction with the prosthesis. Implant-retained dentures have been developed and studied as a method for solving the problem of instability associated with conventional dentures. Ten edentulous patients of age group 60 to 70 years were selected to participate in within subject cross over clinical trial. Complete dentures were fabricated which were later converted to implant retained overdentures. Presurgical dentascan was done with the surgical stent. The bite force measurements taken with conventional dentures and the implant supported dentures after 4 and 16 weeks of prosthetic loading of the implants. Patient's opinions were assessed by means of questionnaires with precoded response categories. The results obtained in study showed that there was statistical increase in the maximum bite force of the conventional dentures from patients without dentures and for implant retained mandibular overdentures in comparison to conventional dentures. The percentage of patients satisfied with their conventional dentures in general was about $20 \%$, and almost all patients were not satisfied with mandibular conventional denture. Compared to $45 \%$ patients satisfied with implant retained mandibular overdenture in general whereas almost all the patient's were satisfied with the retention and speech of their implant retained mandibular overdenture dentures.
\end{abstract}

Keywords: Implant-retained dentures, Denta scan, Bite force measurement, Patient satisfaction.

\section{INTRODUCTION}

Patients who wear conventional dentures often complain about the instability of the prosthesis, particularly the mandibular denture. Denture instability leads to a feeling of insecurity, inefficient mastication, and overall dissatisfaction with the prosthesis. ${ }^{1}$ Implant-retained dentures have been developed and studied as a method for solving the problem of instability associated with conventional dentures. Both fixed and removable implantretained complete dentures have evolved over the past 15 years. Implant-retained dentures have many advantages compared to conventional complete dentures. ${ }^{1,2}$ Physical retention is limited in patients with significant bone resorption, since the supporting surface is greatly reduced and stability of the lower denture is provided mainly by the action of the musculature.

Bite force is one indicator of the functional state of the masticatory system that results from the action of jaw elevator muscles modified by the craniomandibular biomechanics. ${ }^{3}$ Maximum bite force level in complete denture wearers has been limited to an extent due to the sensitivity or pain of the mucoperiosteum covering the mandibular edentulous ridge which gets sandwiched in between the dentures and bone. ${ }^{3,4}$ Complete denture wearers reported more frequent pain in the mandible than in the maxilla. There is difference in the maximum bite force level seen between the patients who wear conventional dentures and implant-retained mandibular overdentures. Biting force with mandibular implant-retained overdenture is $170 \mathrm{~N}$ with tooth-retained overdenture is $120 \mathrm{~N}$ and with complete denture is $100 \mathrm{~N}^{4-6}$

There is a need to draw a comparison between the complete dentures and implant-retained dentures, the aim of this within subject crossover clinical trial was to quantitatively evaluate and compare the maximum biting force values and patient satisfaction of the two groups with conventional dentures and implant-retained overdentures.

\section{MATERIALS AND METHODS}

Ten edentulous patients of age group 60 to 70 years were selected to participate in within subject crossover clinical trial in Department of Prosthodontics, KD Dental College, Mathura. The patients were given code number 1 to 10 . All patients complained of reduced stability and insufficient retention of their mandibular dentures. Complete dentures were fabricated which were later converted to implantretained overdentures. Written informed consent was obtained from all participants. Presurgical dentascan (Fig. 1) was done with the surgical stent in the patient's mouth and the information from the dentascan was assessed for the 

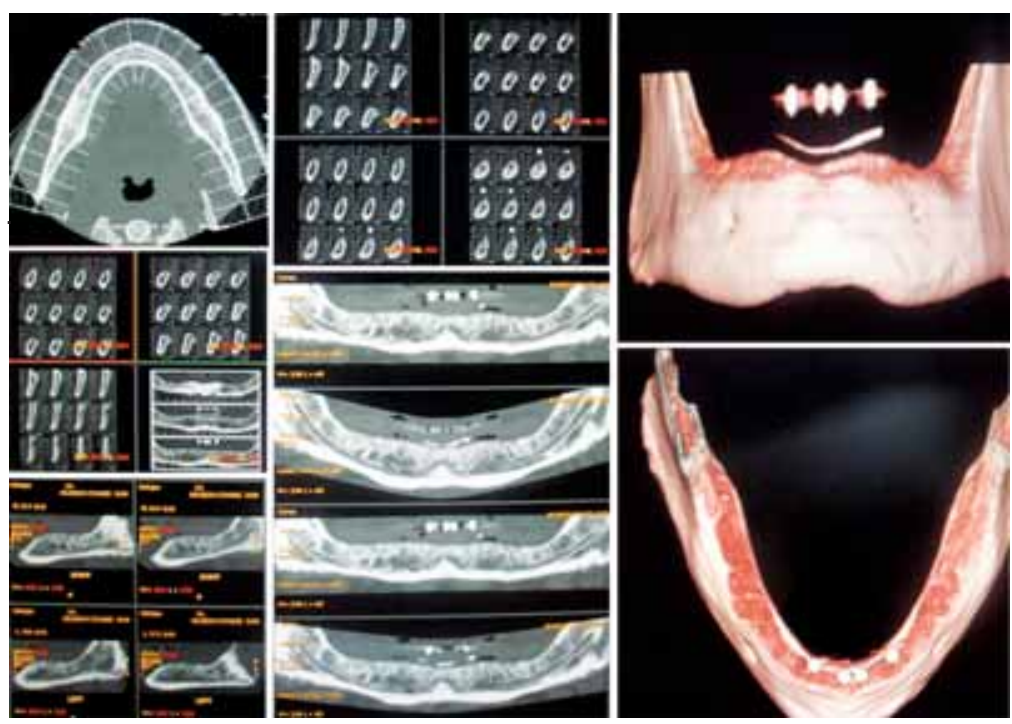

Fig. 1: Preoperative dentascan

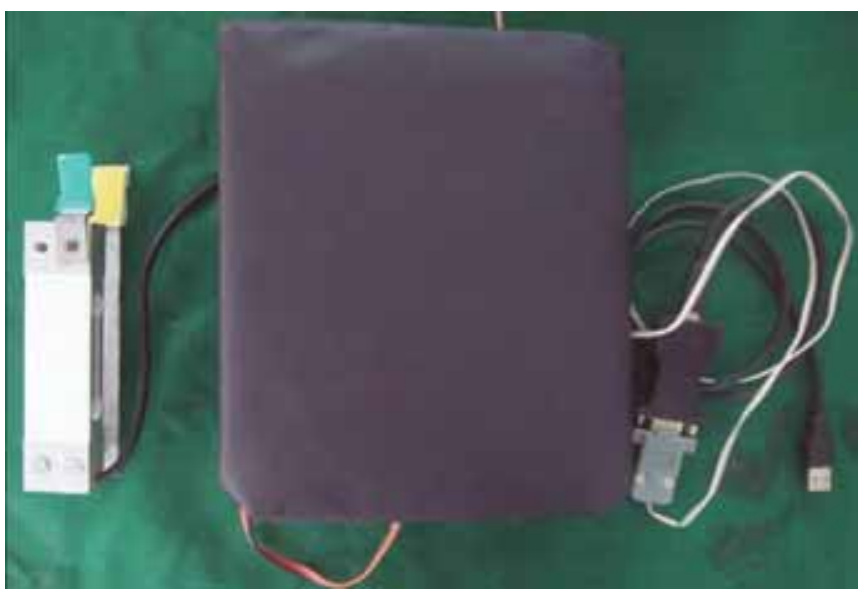

Fig. 2: Stain gauge transducer measuring circuit

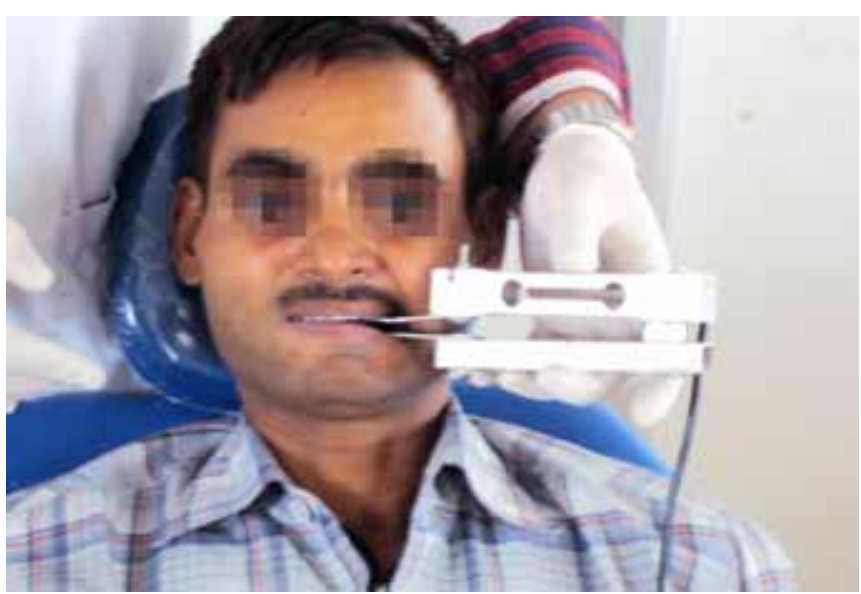

Fig. 3: Intraoral bite force measurements

placement of two implants in the interforaminal region according to standard technique.

Bite force analysis was carried out with stain gauge bite force transducer (Fig. 2) for conventional complete dentures. The device was calibrated in vitro on a master cast, the transducer was covered on both the upper and lower side by rubber dam attached by $2 \mathrm{~mm}$ thick double-sided adhesive tapes. ${ }^{6}$ Biting fork was placed between the antagonist teeth while at the same time, the occlusion was stabilized contralaterally with a rubber block. ${ }^{7}$ Subjects were instructed to bite on their maximum force.

Measurements involved five biting positions: Between first molars of the right and left sides of the jaw, between canines of both sides of the jaw and between central incisors. ${ }^{7}$ Measurements were started at the right molar following the dental arch toward the left molar, with one minute rest between trials, and were repeated once. ${ }^{7}$ The force measurements are taken with conventional dentures and the implant supported dentures after 4 and 16 weeks of prosthetic loading of the implants (Fig. 3).

\section{Patient Satisfaction}

Patient's opinions were assessed by means of questionnaires with precoded response categories prior to treatment and 20 weeks after loading the implants and conversion of conventional dentures into implant-retained overdenture. This questionnaire consisted of nine items concerning the function of the dentures in general and the maxillary and mandibular dentures separately. Each item could be answered on a three point rating scale (1-satisfied, 2 -neutral, 3-dissatisfied). ${ }^{8}$ The data obtained at the 6 months evaluation were used to analyze the differences between the groups and presented as distribution in percentage of response. The data of the denture satisfaction questionnaire of the conventional denture are presented as reference. $^{8}$

\section{RESULTS}

\section{Unilateral Bite Force Measurements}

The bite force values obtained from the patients without dentures served as a control and baseline for comparison of the bite force values with conventional dentures and implantretained mandibular overdentures after 4 weeks of loading and implant-retained mandibular overdentures after 16 weeks of loading. To evaluate the data the mean of bite 


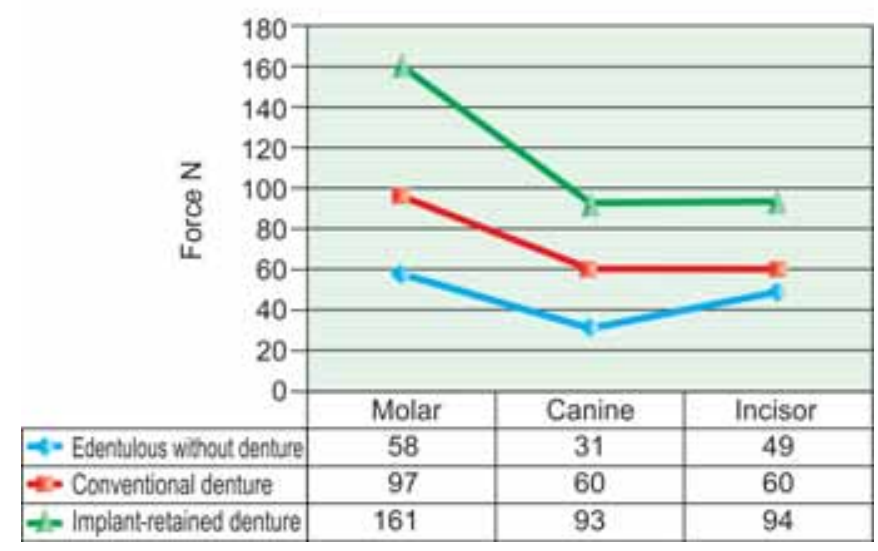

Fig. 4: Mean maximum bite force

force values at right and left molars, canines and incisors was taken.

Difference in maximum forces exerted by subjects with dental implants were statistically significant, at molar position, with those of the complete denture $(p>0.01)$ and edentulous group ( $p>0.01)$, and were even statistically significantly different for implant denture group than those of the complete denture $(\mathrm{p}<0.001)$ and edentulous group $(\mathrm{p}<0.001)$ at the canine region (Fig. 4).
Nevertheless, no statistical differences could be observed between the edentulous group and complete denture groups (p-values $>0.06$ ) at the incisor region even though there was difference in the maximum bite force values but the difference in the maximum bite force values was not that large as in case of molar and canine. Although there was statistically significant difference between the maximum bite force of the implant group and conventional denture group $(p>0.009)$ at the incisor region, there was no statistical difference in maximum bite force between the implant group after 4 weeks of loading and 16 weeks of loading at all three positions viz molars, canines and incisor.

The maximum bite force of the implant group was significantly larger than the force of the conventional denture and edentulous group at molar position, with $161 \mathrm{~N}, 97 \mathrm{~N}$ and $58 \mathrm{~N}$ respectively. And at canine region, maximum bite force for implant denture, conventional denture and edentulous group was $93 \mathrm{~N}, 60 \mathrm{~N}$ and $31 \mathrm{~N}$ respectively. The maximum bite force value at incisor region for the implant group, conventional denture group and edentulous group were $94 \mathrm{~N}, 60 \mathrm{~N}$ and $49 \mathrm{~N}$ respectively. There was no statistical difference between the maximum bite force of delayed and immediately loaded implant-retained mandibular overdentures. The bite force values obtained with the delayed loaded implants of implant-retained mandibular overdentures and immediately loaded implant-

Table 1: Distribution in percentages of responses on denture satisfaction questionnaire

\begin{tabular}{|c|c|c|c|}
\hline & Response & Conventional dentures & $\begin{array}{l}20 \text { weeks after implant-retained overdenture } \\
\text { prosthesis fabrication }\end{array}$ \\
\hline $\begin{array}{l}\text { Are you satisfied or dissatisfied } \\
\text { with your dentures in general? }\end{array}$ & $\begin{array}{l}1 \\
2 \\
3\end{array}$ & $\begin{array}{l}20 \\
40 \\
40\end{array}$ & $\begin{array}{r}45 \\
55 \\
0\end{array}$ \\
\hline Your upper denture? & $\begin{array}{l}1 \\
2 \\
3\end{array}$ & $\begin{array}{r}30 \\
70 \\
0\end{array}$ & $\begin{array}{l}45 \\
45 \\
10\end{array}$ \\
\hline Your lower denture? & $\begin{array}{l}1 \\
2 \\
3\end{array}$ & $\begin{array}{r}0 \\
10 \\
90\end{array}$ & $\begin{array}{r}89 \\
11 \\
0\end{array}$ \\
\hline Retention of your upper denture? & $\begin{array}{l}1 \\
2 \\
3\end{array}$ & $\begin{array}{r}50 \\
50 \\
0\end{array}$ & $\begin{array}{l}22 \\
67 \\
11\end{array}$ \\
\hline Retention of your lower denture? & $\begin{array}{l}1 \\
2 \\
3\end{array}$ & $\begin{array}{l}10 \\
10 \\
80\end{array}$ & $\begin{array}{r}100 \\
0 \\
0\end{array}$ \\
\hline Speech? & $\begin{array}{l}1 \\
2 \\
3\end{array}$ & $\begin{array}{l}20 \\
30 \\
50\end{array}$ & $\begin{array}{r}100 \\
0 \\
0\end{array}$ \\
\hline Appearance of denture? & $\begin{array}{l}1 \\
2 \\
3\end{array}$ & $\begin{array}{r}70 \\
30 \\
0\end{array}$ & $\begin{array}{r}89 \\
11 \\
0\end{array}$ \\
\hline Is your upper denture causing pain? & $\begin{array}{l}1 \\
2 \\
3\end{array}$ & $\begin{array}{l}10 \\
40 \\
50\end{array}$ & $\begin{array}{l}22 \\
67 \\
11\end{array}$ \\
\hline Is your lower denture causing pain? & $\begin{array}{l}1 \\
2 \\
3\end{array}$ & $\begin{array}{l}50 \\
30 \\
20\end{array}$ & $\begin{array}{r}0 \\
23 \\
77\end{array}$ \\
\hline
\end{tabular}

Response to question 1 to 7: 1—satisfied; 2-neutral; 3-dissatisfied, response to question 8 and 9: 1—often; 2—seldom; 3—never 
retained mandibular overdentures was almost same; both at 4 weeks after loading and 16 weeks of loading at the molar, canine and incisor region.

\section{Patient Satisfaction}

Patient satisfaction was assessed with descriptive analysis as distribution in percentages of responses on denture satisfaction (Table 1). The percentage of patients satisfied with their conventional dentures in general was about $20 \%$, and almost all patients were not satisfied with mandibular conventional denture. Compared to $45 \%$ patients satisfied with implant-retained mandibular overdenture in general whereas almost all the patients were satisfied with the retention and speech of their implant-retained mandibular overdenture dentures. The mandibular implant-retained overdentures also resulted in lesser number of patient experiencing pain of mucosa in relation to the mandibular denture as compared to conventional dentures.

\section{DISCUSSION}

While most implant-based treatment has been historically focused on fixed prosthodontic tooth replacement, the multitude of benefits to the edentulous population from implant overdentures is overwhelming in terms of improved function, emotional stability, physical health and esthetics. Proper evaluation and treatment planning of the fully edentulous patient has been shown to result in an improved quality of life for patients and predictable results leading to clinical success. ${ }^{9}$ The results obtained in our study showed that there was an increase in the maximum bite force of the conventional dentures from edentulous state without dentures from $58 \mathrm{~N}$ to $97 \mathrm{~N}$ in the molar region whereas for implant-retained mandibular overdentures in comparison to conventional dentures from $97 \mathrm{~N}$ to $160 \mathrm{~N}$ in the molar region which was seen in accordance with the previous findings. ${ }^{6,7,10}$ Maximum bite forces in the molar region were almost twice as high in subjects with mandibular implantretained overdentures compared with complete denture wearers. These differences were expected, since improvements in bite force by dental implants have been observed in several other studies (Haraldson et al, 1988; Lindquist and Carlsson, 1982, 1985; Carlsson and Lindquist, 1994). ${ }^{11}$

And even there was increase in maximum bite force in incisor region from $49 \mathrm{~N}$ to $60 \mathrm{~N}$ from edentulous patient group compared to conventional complete denture group whereas for implant-retained mandibular overdenture was $94 N^{7}$ There was no significant increase in the maximum bite force seen for implant-retained mandibular overdentures after 14 weeks of prosthetic loading in relevance to 4 weeks after prosthetic loading.

Mericske-Stern (1997) ${ }^{12}$ also did a study on 5 patients with two ITI (Straumann) implants each. The mean bite force obtained in the patients was $9.82 \mathrm{kgf}$. In the study of Mericske-Stern, the mean age of the 11 patients was 74 years, which was 15 years older than the mean age of patients in the present study (59 years). This is thought to be attributed to the different age range of the patients of the two studies. Maximum bite force of conventional denture subjects was only 20 to $40 \%$ that of dentate subjects in accordance to previous findings (Helkimo et al, 1977; Haraldson et al, 1979; Slagter et al, 1993; Fontijn-Tekamp et al, 2000). ${ }^{10}$

\section{Patient Satisfaction}

Although the overall satisfaction level was quite high (95\%) for implant-retained mandibular overdenture compared to conventional complete dentures in accordance with Boerrigter (1998). ${ }^{11}$ No demographic variables were related to the overall satisfaction at a statistically significant level. These results are in agreement with those of Maria E Geertman, Marinus AJ van Waas (1996). ${ }^{13}$

The present study reported that $89 \%$ of the patients were satisfied with the appearance of implant-retained overdenture which was in accordance with Chang et al (1994). ${ }^{14}$ Almost all the patients were satisfied with the retention of the mandibular denture in case of implantretained overdenture and only 20\% were satisfied with retention in case of conventional complete denture which was in accordance to the finding of Maria E Geertman, Marinus AJ van Waas (1996).

The study showed that the $80 \%$ patients with conventional complete dentures complained of pain under their mandibular dentures whereas, only $23 \%$ of patients with implant-retained mandibular overdenture reported pain which was similar to finding by other investigators (D Wismeijer, MAJ Waas, van Waas, Kalk 1997). KT Suga, GE Carlsson (1998) stated that subjects with few or no remaining natural teeth and removable dentures, and besides that a restricted bite force, said they had no or only few problems with mastication.

\section{CONCLUSION}

The following conclusions can be drawn from the results of this preliminary investigation:

1. The maximum biting force increased significantly ( $\mathrm{p} \leq 0.01$ ) in this patient population when provided with a mandibular tissue-integrated prosthesis (both mean and maximum difference). The increase was significant in case of molar, canine and incisor regions when compared to bite force of conventional complete dentures and edentulous state. Whereas, the increase in the maximum bite force in the region of molar and canine was significant for conventional complete denture when compared to edentulous state but the increase in the maximum bite force in the incisor region was not statistically significant for conventional complete denture when compared against the maximum bite force of edentulous people. 
2. The maximum biting force in the complete denture population had a wide range.

3. The maximum biting force in the tissue-integrated prosthesis population had a wide range.

4. There was no statistically significant increase in the maximum bite force of implant-retained mandibular overdentures over time period from 4 weeks of loading to 16 weeks of loading.

5. There was no statistically significant difference in the maximum bite force values of implant-retained overdentures which were delayed loaded compared to implant-retained mandibular overdentures constructed over immediately loaded implants.

6. The patients after receiving implant retained mandibular overdentures were significantly more satisfied towards their dentures as compared to conventional complete dentures. All the patients reported decrease in the pain under mandibular dentures along with almost 100\% satisfaction toward retention for the mandibular denture and improvement in speech and esthetics.

\section{REFERENCES}

1. Daniela Nardi Mancuso, Marcelo Coelho Goiato: Bite force and masticatory efficiency in implant-retained dentures literature review: Dentistry Today, 2008.

2. Kimoto Katsuhiko, Garret Neal R. Effect of mandibular ridge height on masticatory performance with mandibular conventional and implant-assisted overdentures. Int Journal of Oral and Maxillafacial Implants 2003;18(4).

3. Duygu Koc, Arife Dogan, Bulent Bek. Bite force and influential factors on bite force measurements: A literature review. Eur $\mathrm{J}$ Dent 2010;4(2):223-32.
4. Fontijn-Tekampl FA, Slagter AP, vant Hof MA, Geertman ME, Kalk W. Bite forces with mandibular implant-retained overdentures. J Dent Res 1998;77(10):1832-39.

5. Mansour Rismanchian, Farshad Bajoghli, Zahra Mostajeran, Akbar Fazel P sadr Eshkevari. Effect of implants on maximum bite force in edentulous patients. Journal of Oral Implantology 2009;35(4).

6. Frauke Miiller, M Robin. Heath and Rudolf Ott. Maximum bite force after the replacement of complete dentures. Gerodontology 2001;18(1).

7. Fontijn-Tekamp FA, Slagter AP, van’t Hof MA, Kalk W, Jansen JA. Biting and chewing in overdentures, full dentures, and natural dentitions. J Dent Res 2000;79(7):1519-24.

8. Geertman Maria E, van Waas. Denture satisfaction in comparative of implant-retained mandibular overdentures: A randomized clinical trial. Int $\mathrm{J}$ oral maxillofacial implants 1996;11:194-200.

9. Vogel Robert C. Implant overdentures: A new standard of care for edentulous patients current concepts and techniques functional esthetics and restorative dentistry: Series 1, number 2.

10. Haraldson Torgny, Carlsson Gunnar E. Bite force and oral function in patients with osseointegrated oral implants: Scand Dent Res 1977;85:200-08.

11. Fontijn-Tekamp FA, Slagter AP, van't Hof MA, Geertman ME, Kalk W. Bite forces with mandibular implant-retained overdentures. J Dent Res 1998;77:832-39.

12. Regina Mericske-Stern, Jochen Hofmann, Ansgar Wedig. In vivo measurements of maximal occlusal force and minimal pressure threshold on overdentures supported by implants or natural roots: A comparative study, part 1; JOMI 1993;641-49.

13. Brennan Maire, Houston Frank, O’Sullivan Michael, O’Connell Brian. Patient satisfaction and oral health-related quality of life outcomes of implant overdentures and fixed complete dentures. The International Journal of Oral and Maxillofacial Implants 2010;25(4).

14. Khalid S, Haneen. Patient satisfaction with dental implants in riyad, Saudi Arabia; Saudi Dent J 2007;19(2). 